\title{
A high performance grid connected PV system based on HERIC transformerless inverter
}

\author{
Essam Hendawi \\ Electrical Engineering Department, College of Engineering, Taif University, Saudi Arabia \\ Electronics Research Institute, Egypt
}

\begin{tabular}{l} 
Article Info \\
\hline Article history: \\
Received Feb 9, 2020 \\
Revised Apr 8, 2020 \\
Accepted Apr 22, 2020 \\
\hline Keywords: \\
Boost converter \\
HERIC transformerless inverter \\
Leakage current \\
MPPT \\
PV system
\end{tabular}

\begin{abstract}
This paper presents an effective single phase grid connected photovoltaic PV system based on High Efficiency and Reliable Inverter Concept HERIC transformerless inverter. dc-dc boost converter controlled by incremental conductance IC maximum power point tracker MPPT is employed to achieve the maximum extraction power of the PV panels. Proportional integral PI controller controls the output voltage of the boost converter to meet the utility grid requirements. LCL filter is utilized to keep the inverter voltage very close to sinusoidal shape. Employing the HERIC transformerless inverter reduces significantly the ground leakage current beyond safe limits. Semiconductors losses are studied to investigate the efficiency of the proposed system at different insolation levels. Simulation results verify the high performance of the proposed system when considering leakage current and system efficiency.
\end{abstract}

Copyright $\odot 2020$ Institute of Advanced Engineering and Science. All rights reserved.

\section{Corresponding Author:}

Essam Hendawi,

Electrical Engineering Department,

College of Engineering,

Taif University, Tarif, Saudi Arabia.

Email: esam_hendawi@hotmail.com

\section{INTRODUCTION}

The Solar photovoltaic (PV) are considered as the most promising renewable energy sources, which can meet the future energy demands and overcome environmental pollution problems [1-3]. PV systems can deliver energy either to the utility grid or standalone systems. The percentage of PV energy to standalone loads is very small as compared to the PV energy delivered to utility grid. The optimal utilization of PV generated power and the absence of storage batteries are the most important advantages of grid connected systems over standalone ones.

Dc/ac inverters followed with a line transformer are employed [3] to connect PV panels to utility grid. Either a high-frequency transformer (connected to the PV panels) or a low-frequency transformer at the output stage of the inverter is used. The line transformer achieves two main goals; the first is the galvanic isolation between the PV panels and the utility grid and consequently realize personal safety. The second is raising the output voltage of the inverter to a suitable value to meet the utility grid voltage. The line transformer attenuates the grid DC injection current and therefore improves the grid's power quality. In contrast to line transformer advantages, it has many disadvantages such as large-system volume, large weight, and high cost. As a result the line transformer are rarely used nowadays in grid connected PV systems. Unfortunately, the absence of line transformer results in lack of galvanic isolation which in turn leads to some safety issues. A parasitic capacitor exists between the PV panels and ground where a leakage current flows through this capacitor. The leakage current increases the system losses, distorts the output current, induces radiated electromagnetic interference and causes personal safety problems. Therefore, the leakage current must be reduced to recommended limits [4]. The leakage current exists as the 
common mode voltage (CM) of the inverter changes. Therefore, the changes of the common mode voltage must be minimized to reduce the leakage current. Transformerless inverters are the best solution to overcome the problem of leakage current as listed in the literature [5-15]. Transformerless inverters have recently become more popular owing to its small system volume, low weight and low cost. Several topologies of transformerless inverters are introduced including single phase and three phase inverters. Each topology has its own circuit configuration, performance analysis, advantages and disadvantages when the following points of view are considered: (1) ability of reducing the leakage current, (2) number of switches and their total losses (3) system complexity, efficiency and cost. Classifications and comparison between different topologies of transformerless inverters are presented based on the ability of reducing the leakage current, inverter losses and inverter efficiency [16-20]. One of the most common, perfect and efficient transformerless inverter is the High Efficiency and Reliable Inverter Concept (HERIC) [21]. HERIC transformerless inverter is more efficient than many popular transformerless inverters such as H5, H6 and modified H6 transformerless inverters when reduction of leakage current, inverter losses and complexity are taken as comparison criterion between inverters. With higher power, three phase transformerless inverters are employed [22]. With transformer-less systems, researches that take into account the maximum power extraction from the PV panels are very rare although the great importance of this issue in PV systems. This paper proposes a complete single phase PV grid connected system which can achieve the minimization of leakage current and maximization of power drawn from the PV panels as well. HERIC transformer-less inverter is chosen due to its several advantages over its counterparts. dc-dc boost converter is included to raise the output voltage of PV panels to suitable levels to meet the requirements of connection to utility grid. Three controllers are employed in the system. The first is the incremental conductance IC maximum power point tracker. It controls the boost converter switch in such a way that the maximum power is drawn from the PV panels. The second controller is the boost converter output voltage controller where its aim is to keep the inverter dc link voltage at a suitable constant value to meet the requirements of connection with grid. The third controller generate the required control signals to the HERIC inverter switches. LCL filter is inserted at the outer stage of the inverter to cancel the unwanted harmonics. Losses of inverter and boost converter are estimated and consequently the system efficiency is calculated at different sun insolation levels.

\section{PROPSED SYSTEM CONFIGURATION}

Figure 1 presents the MATLAB/SIMULINK model of the proposed PV grid connected system. The proposed system consists mainly of PV panels, dc-dc boost converter, HERIC transformerless inverter, LCL filter and controllers. The following sections describe each part of the proposed system.

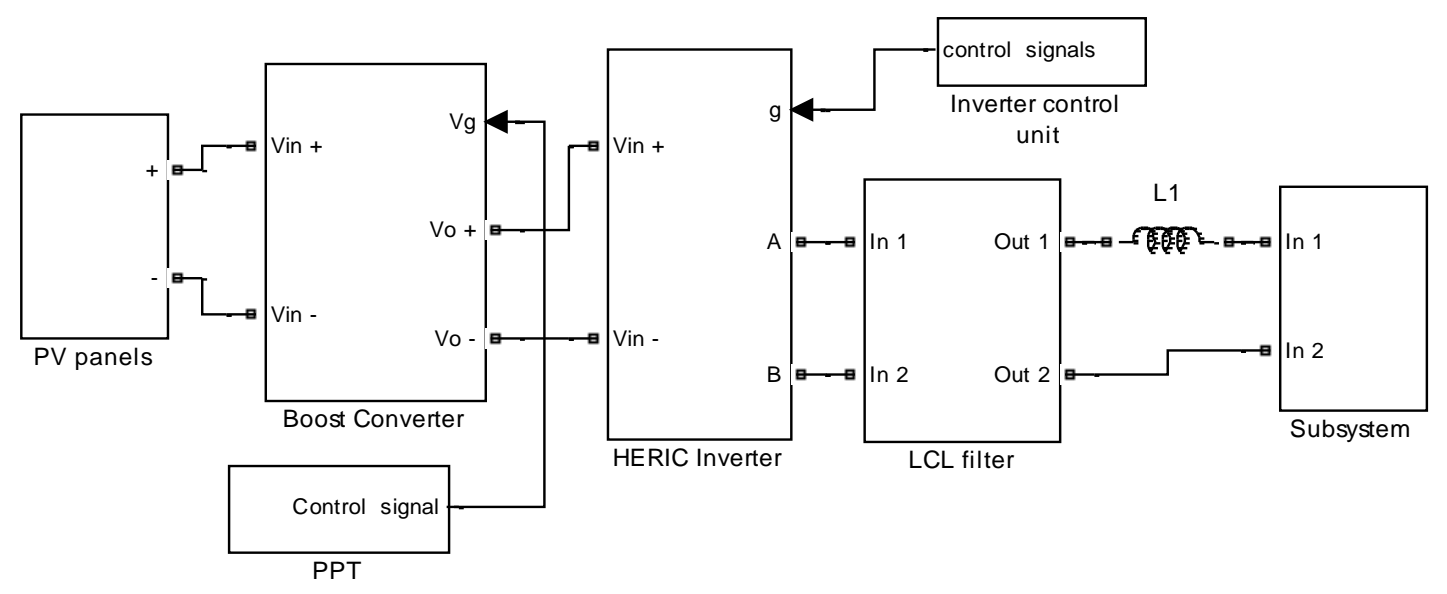

Figure 1. The proposed grid connected PV system

\subsection{PV panels}

The PV panels consists of 720 series modules to attain the suitable voltage for the boost converter and in turn achieve the required dc link voltage. The parameters of the PV panels are presented in Table 1 for $100 \%$ sun insolation. 


\begin{tabular}{cc} 
Table 1. PV array parameters at $100 \%$ insolation level \\
${ } }$ & 422 \\
Short circuit current (A) & 15.2 \\
Maximum power (W) & 1209 \\
Voltage for maximum power $\mathrm{V}_{\text {pmax }}(\mathrm{V})$ & 346.5 \\
Current for maximum power $\mathrm{I}_{\mathrm{pmax}}(\mathrm{A})$ & 3.49 \\
\hline
\end{tabular}

\subsection{Boost converter}

The conventional boost circuit consisting of inductor, diode, capacitor and switch is utilized. The relation between the converter input voltage $\mathrm{V}_{\mathrm{i}}$ (PV panels voltage) and the converter output voltage $\mathrm{V}_{\mathrm{O}}$ is known as:

$$
\mathrm{V}_{\mathrm{O}}=\mathrm{V}_{\mathrm{i}} /(1-\mathrm{D})
$$

The duty cycle ' $\mathrm{D}$ ' of the converter switch is controlled by the maximum power point tracker such that ' $\mathrm{V}_{\mathrm{i}}$ ' is kept at a value corresponding to the maximum power at any sun insolation level.

\subsection{HERIC transformer-less inverter}

HERIC transformer-less inverter as illustrated in Figure 2 employs two extra switches added to the conventional full bridge inverter. The additional switches $S_{5}$ and $S_{6}$ are connected back to back. During freewheeling periods, $S_{5}$ and $S_{6}$ with their antiparallel diodes disconnect the PV-panels from the grid. Operation of the inverter is based on the following rules:

a) The signals of $S_{5}$ and $S_{6}$ are square waves synchronized to the grid voltage, where $S_{5}$ conducts during positive half cycle with the antiparallel diode of switch $S_{6}$ while $S_{6}$ conducts during negative half cycle with the antiparallel diode of switch $\mathrm{S}_{5}$.

b) The switches $\mathrm{S}_{1}$ and $\mathrm{S}_{4}$ of the H-bridge conduct simultaneously at the switching frequency during positive half cycle.

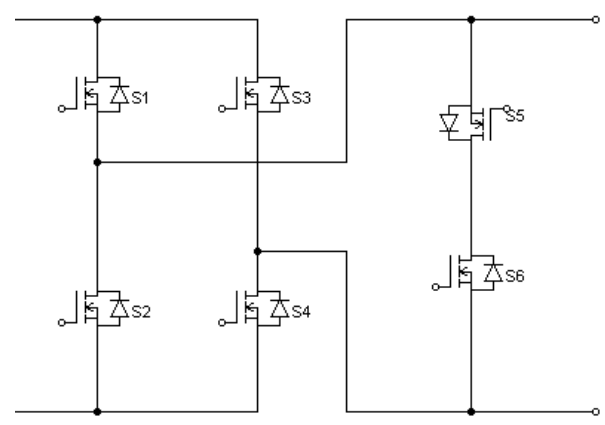

Figure 2. HERIC inverter

The switches $S_{2}$ and $S_{3}$ of the H-bridge conduct simultaneously at the switching frequency during negative half cycle. The equivalent circuits of HERIC inverter during modes of operation are given in Figure 3. There are four modes of operation during each cycle as follows:

Mode 1: Switches $S_{1}, S_{4}$ and $S_{5}$ conduct together. In this case, the path of the current is (boost converter $-S_{1}$ - LCL filter and grid $-\mathrm{S}_{4}$ - boost converter). This mode is called active mode during positive half cycle. In this mode the inverter output voltage equals $\mathrm{V}_{\mathrm{dc}}$

Mode 2: Freewheeling mode in positive half cycle. In this mode the switch $S_{5}$ with the antiparallel diode of switch $\mathrm{S}_{6}$ conduct together resulting in grid current freewheeling and in this case the inverter output voltage equals zero. The PV panels are disconnected from the utility grid during this mode.

Mode 3: Switches $S_{2}, S_{3}$ and $S_{6}$ conduct together. In this case, (boost converter $-S_{3}-L C L$ filter and grid $\mathrm{S}_{2}$ - boost converter). This mode is called active mode during negative half cycle. In this mode the inverter output voltage equals $-\mathrm{V}_{\mathrm{dc}}$

Mode 4: Freewheeling mode in negative half cycle. In this mode the switch $S_{6}$ with the antiparallel diode of switch $\mathrm{S}_{5}$ conduct together resulting in grid current freewheeling and in this case the inverter output voltage equals zero. Also the PV panels are disconnected from the utility grid during this mode. 


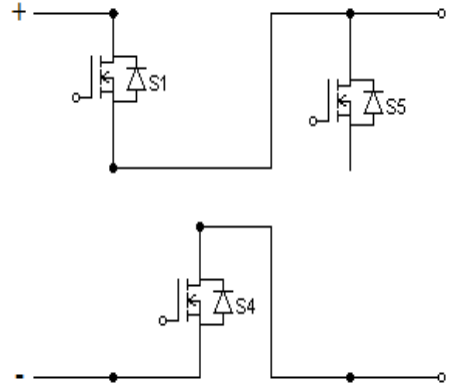

(a) mode 1

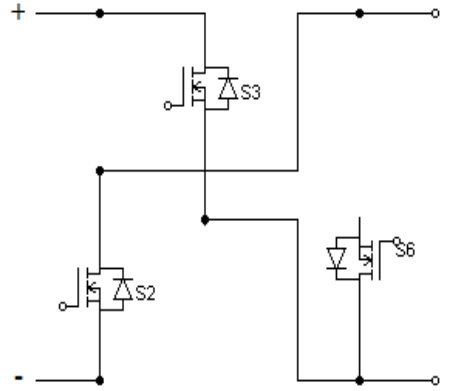

(c) mode 3

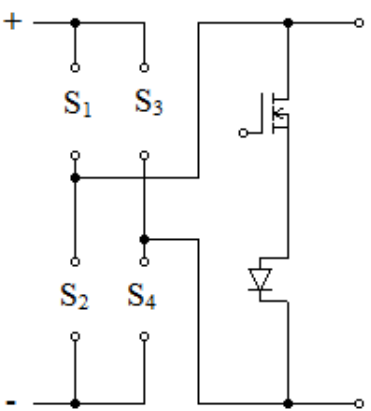

(b) mode 2

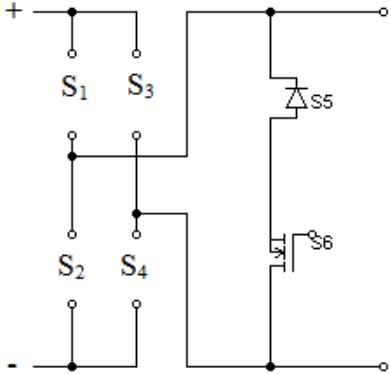

(d) mode 4

Figure 3. Equivalent circuit of HERIC inverter during modes of operation

\section{SYSTEM CONTROLLERS}

Methods of controlling the extracted power from the PV panels, boost converter controller and generation of control signals for HERIC transformer-less inverter switches are proposed in this section.

\subsection{Maximum power point tracker (MPPT)}

The well-known model of PV panels consists of current source, parallel diode, parallel resistance and series diode. The equations relating the current, voltage and power of PV panels are utilized in a matlab m-file to model the PV panels. The P-V characteristics at different insolation levels $(100 \%, 60 \%$ and $40 \%)$ are illustrated in Figure 4.

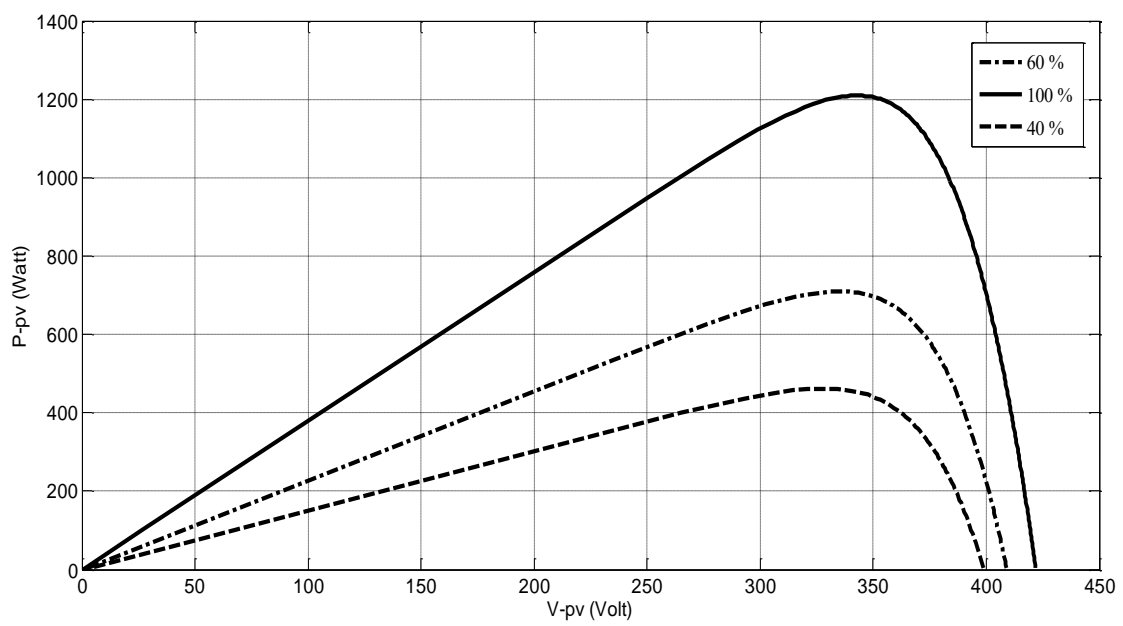

Figure 4. PV characteristics at different insolation levels 
PV panels can be connected in parallel or series for higher total output current or voltage respectively. The output voltage is still uncontrolled and it may vary according to environmental conditions of PV panels. To solve this problem and achieve maximum power extraction from the PV panels, a dc-dc boost converter is utilized to raise the output voltage at a level that meets the utility grid requirements. Many MPP trackers are listed in the literature [23-25]. In this research, the incremental conductance (IC) MPPT is applied to control the duty cycle of the dc-dc boost converter switch so that the output voltage of the PV panels always follow the value corresponding to the maximum power. The algorithm of IC as presented in Figure 5 is briefly summarized as follows:

The derivative of $\mathrm{PV}$ power $(\mathrm{P})$ with respect $\mathrm{PV}$ voltage $(\mathrm{V})$ is

$$
\frac{d P}{d V}=V \cdot \frac{d I}{d V}+I
$$

$I$ is the PV current. Rearranging the previous equation yields to

$$
\frac{d I}{d V}=-\frac{I}{V}+\frac{1}{V} \cdot \frac{d P}{d V}
$$

The condition of maximum power is:

$$
\frac{d P}{d V}=0
$$

The PV power increases as $\mathrm{PV}$ voltage increases $(\mathrm{dP} / \mathrm{dV}$ is positive) until the maximum power point then $\mathrm{PV}$ power decreases as $\mathrm{PV}$ voltage increases $\left(\mathrm{dP} / \mathrm{dV}\right.$ is negative). Therefore, $\frac{d I}{d V}$ is greater than $-\frac{I}{V}$ at the left to the point of $\mathrm{P}_{\max }$ and $\frac{d I}{d V}$ is less than $-\frac{I}{V}$ at the right to the point of $\mathrm{P}_{\max }$ Incremental Conductance algorithm is carried out in the following steps:

a) Read the PV output current $\left(\mathrm{I}_{\mathrm{pv}}\right)$ and voltage $\left(\mathrm{V}_{\mathrm{pv}}\right)$ then calculate the PV output power $\mathrm{P}_{\mathrm{pv}}$.

b) Calculate increment of the three values.
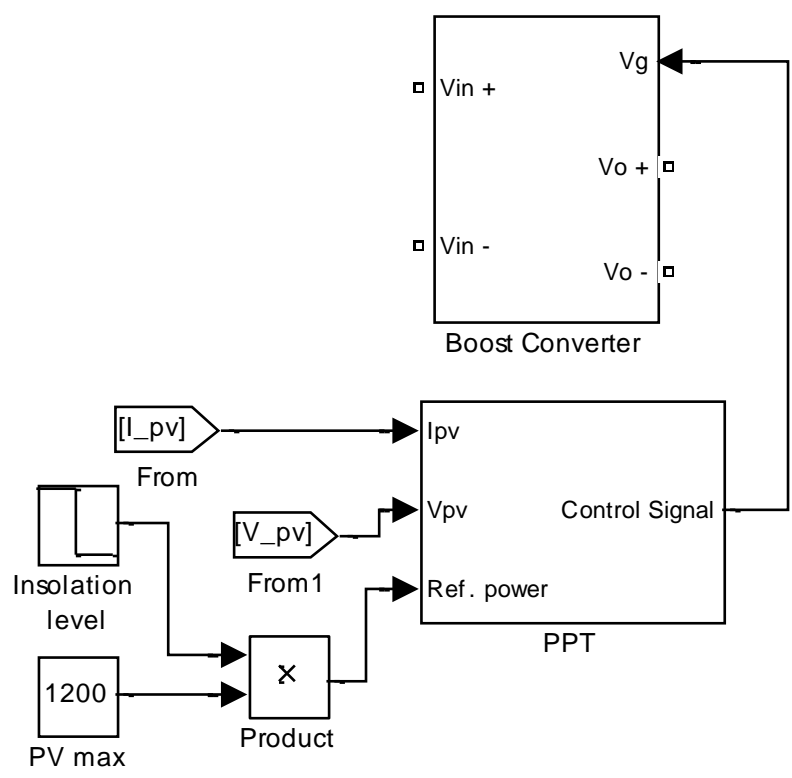

Figure 5. Maximum power point tracker

$$
\begin{aligned}
& \Delta I=I_{p v(n+1)}-I_{p v(n)} \\
& \Delta V=V_{p v(n+1)}-V_{p v(n)} \\
& \Delta P=P_{p v(n+1)}-P_{p v(n)}
\end{aligned}
$$


c) According to the sign of the increments, the duty cycle (D) of the control signal to the boost switch is updated.

$$
\mathrm{D}_{(\mathrm{n}+1)}=\mathrm{D}_{(\mathrm{n})} \pm \Delta \text { duty }
$$

The output of the MPPT algorithm is the control signal of dc-dc boost converter whose output voltage is related to the PV panels' voltage as:

$$
\mathrm{V}_{\text {boost }}=V_{p v} /(1-\mathrm{D})
$$

\subsection{DC-DC boost converter voltage controller}

The output voltage of the boost converter is raised to suitable values for connection to the grid and it always tracks the value corresponding to maximum power. This output voltage varies as the operating conditions of PV panels change. These variations result in great problems on the connection with the grid. Accordingly, a voltage controller is inserted between the boost converter and the HERIC inverter. This controller as shown in Figure 6 is a PI controller the output of which is the grid reference current $\mathrm{I}_{\mathrm{g}-\mathrm{ref}}$.

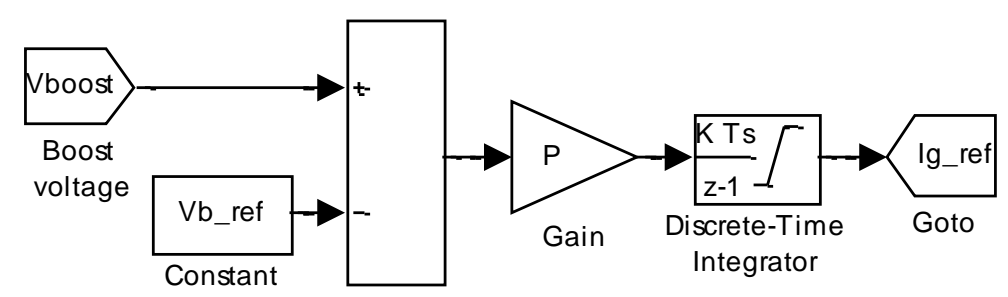

Figure 6. Voltage controller of boost converter output voltage

\subsection{HERIC control signals generation}

The grid voltage $\left(\mathrm{V}_{\mathrm{g}}\right)$, reference grid current and the actual grid current are employed with a phase locked loop (PLL) and PI controller to generate the control signals of switches $S_{1}$ through $\mathrm{S}_{4}$. A comparison of $\left(\mathrm{V}_{\mathrm{g}}\right)$ with zero voltage generates square waves which drive the switches $S_{5}$ and $S_{6}$ during positive and negative half cycle respectively. The phase locked loop achieves the synchronization of connection between the inverter and the grid.

\section{SIMULATION RESULTS AND DISCUSSION}

This section presents performance evaluation obtained through simulation results to verify the effectiveness of the proposed PV grid connected system. The system is simulated using Matlab/Simulink software. The incremental conductance method is employed as an MPP tracker. The algorithm of IC as mentioned in section III.A is written in an m-file. The algorithm receives the present values of PV current and voltage and generate the control signal to the boost converter switch with continuous updating the duty cycle. The boost converter output voltage controller keeps the dc link voltage (input voltage to HERIC inverter) constant at a suitable level to meet grid connection requirements. The controller compares the required reference dc link voltage with the actual boost voltage then a proportional integral PI controller is applied to the error. The proportional and integral gains are 30 and 1 respectively. The output of this controller is the grid reference current $I_{\text {g-ref }}$ The boost converter has an inductance of $100 \mathrm{mH}$ and a capacitor of $1000 \mu \mathrm{F}$. The reference grid current, actual grid current and the phase locked loop circuit are utilized to generate the control signals of HERIC inverter switches $S_{1}$ to $S_{4}$. The switches $S_{5}$ and $S_{6}$ operate at the fundamental frequency during positive and negative half cycle respectively. An LCL filter is inserted between the inverter and grid to get pure sinusoidal voltage $\mathrm{V}_{\text {inv }}$. The inductance and capacitance of the filter are $3 \mathrm{mH}$ and $1.5 \mathrm{nF}$ respectively. A series inductor $\mathrm{L}_{1}(50 \mu \mathrm{H})$ is used to limit higher currents between the PV system and grid. The parasitic capacitance for leakage current path is set at $100 \mathrm{nF}$.

Figure 7 shows the PV panels voltage, current and power with step change of insolation level from $80 \%$ to $100 \%$ at $\mathrm{t}=1 \mathrm{sec}$. The IC MPP tracker always tracks the maximum power from the PV panels. Figure 8 presents the boost converter output voltage $\mathrm{V}_{\text {boost }}$, HERIC inverter output voltage $\mathrm{V}_{\mathrm{AB}}$, and leakage current. The boost converter voltage controller keeps $\mathrm{V}_{\text {boost }}$ nearly constant at $450 \mathrm{~V}$. HERIC output voltage $V_{A B}$ has three levels $V_{d c},-V_{d c}$ and zero where obviously unipolar operation of the inverter is applied to get the zero voltage level during freewheeling periods. 

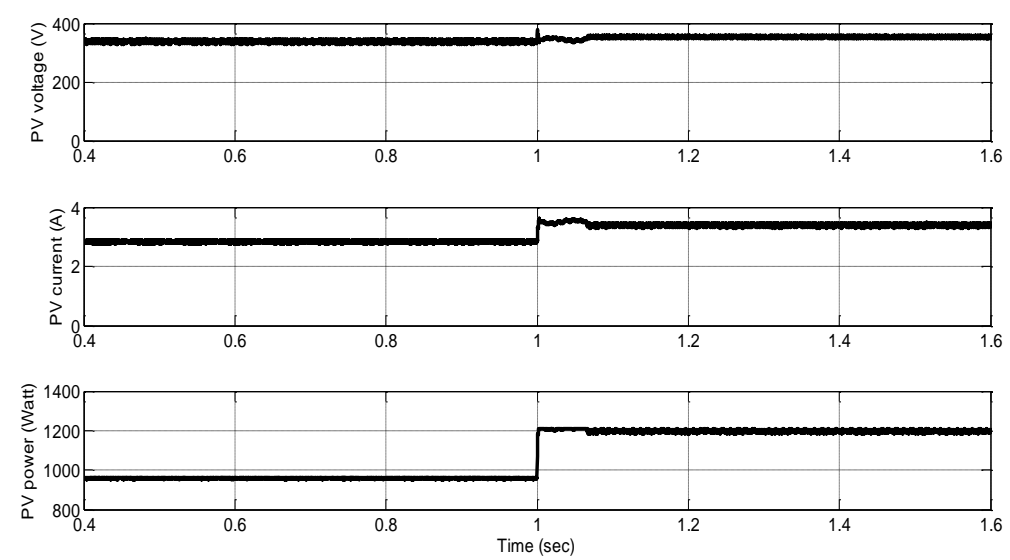

Figure 7. PV panels output voltage, current and power with step change in insolation level at $\mathrm{t}=1 \mathrm{sec}$
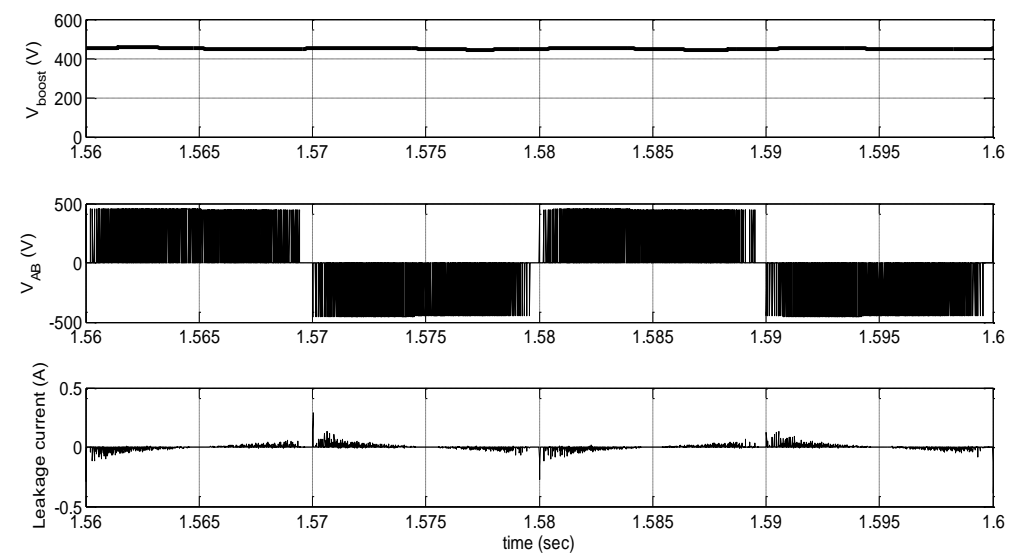

Figure 8. Boost converter output voltage $\mathrm{V}_{\text {boost }}$, HERIC inverter output voltage $\mathrm{V}_{\mathrm{AB}}$, and leakage current

In addition, the bipolar operation is avoided because it results in high ripples in the filter inductors and higher switching losses. The leakage current is very small and it is less than the recommended values (300 mA) [4]. Figures 9 and 10 give the control signals and the currents in the inverter switches respectively at the maximum extracted PV power $(1200 \mathrm{~W})$. The switch $\mathrm{S}_{5}$ and its antiparallel diode conduct in positive and negative half cycle respectively. The opposite operation occurs for $S_{6}$ and its antiparallel diode.

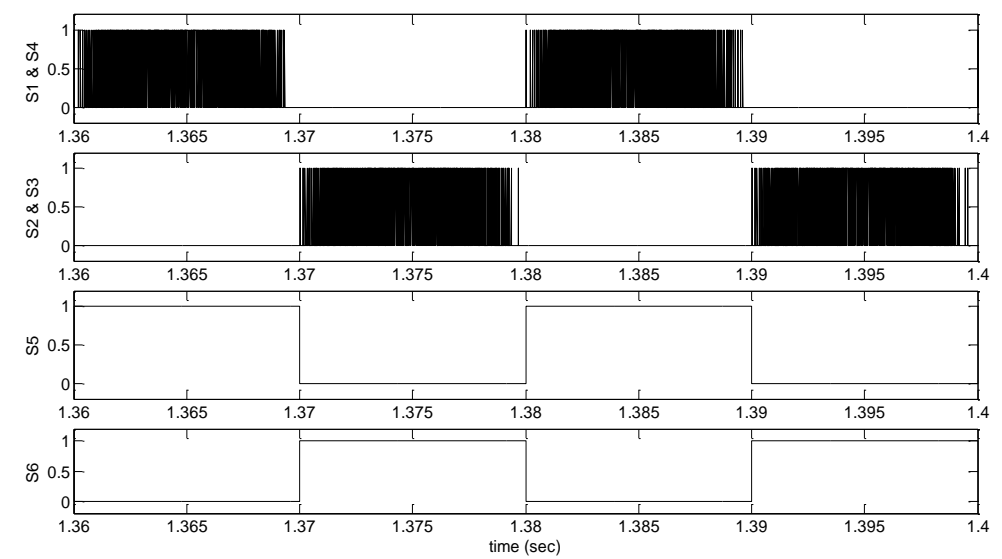

Figure 9. Control signals of HERIC inverter switches 

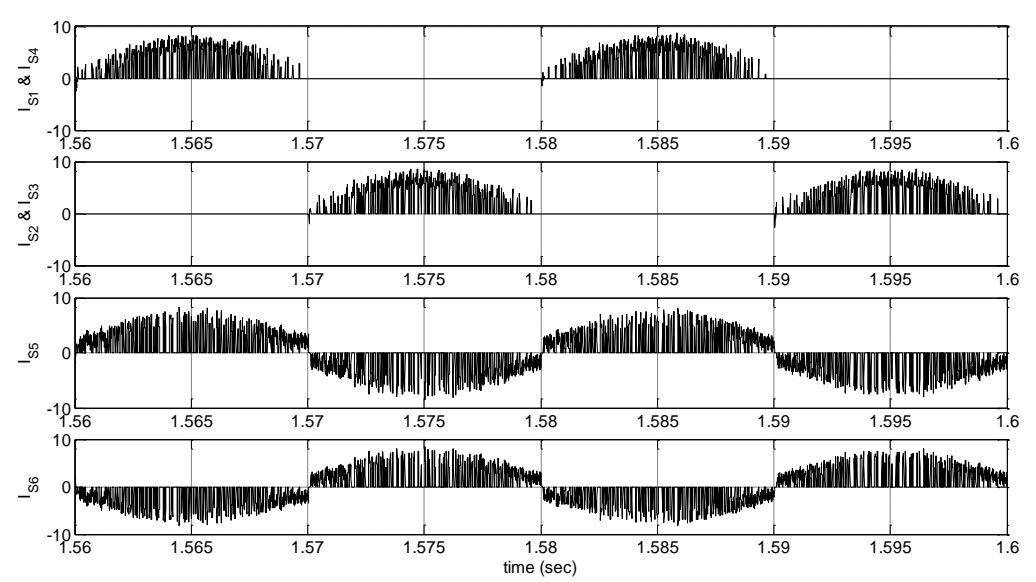

Figure 10. Currents in HERIC inverter switches

\section{EFFICIENCY OF THE PROPOSED SYSTEM}

In addition to the system evalution presented in brevious section, the system performance is evaluated when considering boost converter losses and HERIC inverter losses and consequently the system efficiency is evaluated in this section. The efficiency of the system ' $\eta$ ' is defined as:

$$
\eta=\frac{P_{o u t}}{P_{\text {in }}}=\frac{P_{p v}-\text { Losses }}{P_{p v}}
$$

The main significant losses are the conduction and switching losses in HERIC inverter, boost converter switch and diode. The switch and diode conduction losses can be calculated using the following equations:

Switch conduction losses $\mathrm{P}_{\mathrm{SC}}=\frac{1}{T} \int_{0}^{T} I_{S}^{2} R_{d s, o n} d t$

Diode conduction losses $\mathrm{P}_{\mathrm{SC}}=\frac{1}{T} \int_{0}^{T} I_{D} V_{D F} d t$

Where:

$I_{S}=$ switch conduction current

$I_{D}=$ diode conduction current

$R_{d s, o n}=$ switch on resistance

$V_{D F}=$ Diode forward voltage

The switching losses of the switches can be derived with the help of Figure 11 where the switch current or voltage are approximated by linear lines during the "on" and "off" periods. The switch voltage goes from $\mathrm{V}_{\text {boost }}$ to 0 during "on" period and from 0 to $\mathrm{V}_{\text {boost }}$ during "off" period. The switch current goes from 0 to $i_{s}$ during "on" period and from $i_{s}$ to 0 during "off" period. Therefore, the switch voltage and current during "on" period can be represented as:

$$
\begin{aligned}
& i_{\text {switch }}(t)=i_{S} \frac{t}{t_{\text {on }}} \\
& v_{\text {switch }}(t)=V_{\text {boost }}\left(1-\frac{t}{t_{\text {on }}}\right)
\end{aligned}
$$

The energy dissipated of any switch during "on" and "off" periods $W_{S S}$ is:

$$
W_{S S}=\left(\int_{0}^{t_{o n}} i_{S} \frac{t}{t_{o n}} * V_{\text {boost }}\left(1-\frac{t}{t_{\text {on }}}\right) d t\right)+\left(\int_{0}^{t_{\text {off }}} V_{\text {boost }} \frac{t}{t_{\text {off }}} * i_{S}\left(1-\frac{t}{t_{\text {off }}}\right) d t\right)
$$

Solution of the previous integration is very difficult since the level of the switch current always changes over the fundamental cycle as can be investigated from Figure 10. For simplicity an approximate value of $6 \mathrm{~A}$ is assigned to $\mathrm{i}_{\mathrm{s}}$ " in case of $100 \%$ insolation level. Substituting $\mathrm{V}_{\text {boost }}$ by $450 \mathrm{~V}$ and $i_{\mathrm{s}}$ by $6 \mathrm{~A}$, as shown in 15 is reduced to: 


$$
\begin{aligned}
& W_{S S}=2700 * \int_{0}^{t_{o n}} \frac{t}{t_{o n}}\left(1-\frac{t}{t_{o n}}\right) d t+2700 * \int_{0}^{t_{o f f}} \frac{t}{t_{o f f}}\left(1-\frac{t}{t_{o f f}}\right) d t \\
& =2700 *\left(t_{o n}+t_{o f f}\right) / 6=450 *\left(t_{o n}+t_{o f f}\right)
\end{aligned}
$$

$t_{\text {on }}$ and $t_{\text {off }}$ are determined from the data sheet. The suitable n-channel MOSFET switch to withstand the current as in Figure 10 and voltage $V_{\text {boost }}$ is SPW11N80C3. This chosen MOSFET switch has a turn-on delay time $\left(t_{o n}\right)$ and turn-off delay time $\left(t_{o f f}\right)$ of $25 \mathrm{~ns}$ and $72 \mathrm{~ns}$ respectively. Substituting $t_{\text {on }}$ and $t_{\text {off }}$ in as shown in 17 gives the energy dissipated in one cycle equals $4.365 * 10^{-5} \mathrm{~J}$. The switching frequency is set at $10 \mathrm{kHz}$. Therefore, the switching power losses $\mathrm{P}_{\mathrm{SS}}$ equals the energy dissipated in "one second".

$$
\mathrm{P}_{\mathrm{SS}}=4.365 * 10^{-5} * 10^{4}=0.4365 \mathrm{Watt}
$$

The conduction losses and switching losses for each element in boost converter and HERIC inverter are calculated and then the total system losses and system efficiency are calculated and summarized in Table 2 at different insolation level. Also the utilization factor " $K_{u}$ " is considered in the table. $K_{u}$ is defined as the ratio between the average actual extracted PV power " $P_{p v}$ " to the maximum expected PV power "Pvmax".

$$
K_{u}=\frac{P_{p v}}{P_{p v \max }}
$$

Investigating the results in Table 2 it is noticed that the system efficiency reached nearly $94 \%$ at maximum insolation level. The system efficiency has a high value for $40 \%$ insolation level and above but it decreases for $30 \%$ insolation level and below. The European efficiency " $\eta_{\mathrm{EU}}$ " of the PV system takes into account the changes in insolation level and it is defined as:

Table 2 Maximum PV power, average extracted PV power, output power, system efficiency and

\begin{tabular}{cccccc}
\multicolumn{7}{c}{ system utilization factor } \\
\hline$\%$ insolation level & $P_{\text {pvax }}$ & $P_{p v}$ & $P_{\text {out }}$ & $\eta \%$ & $K_{u}$ \\
\hline 100 & 1200 & 1199 & 1126 & 93.9 & 99.9 \\
90 & 1080 & 1078 & 988 & 91.7 & 99.8 \\
80 & 960 & 958 & 873 & 91.1 & 99.8 \\
70 & 840 & 833.5 & 747 & 89.6 & 99.2 \\
60 & 720 & 708 & 620.5 & 87.6 & 98.3 \\
50 & 600 & 584.5 & 505.6 & 86.5 & 97.4 \\
40 & 480 & 461.5 & 390.7 & 84.7 & 96.1 \\
30 & 360 & 339 & 259 & 76.4 & 94.2 \\
20 & 240 & 219.2 & 131 & 59.8 & 91.3 \\
10 & 120 & 100 & 22.3 & 22.3 & 83.3 \\
5 & 60 & 45 & 6 & 13.3 & 75 \\
\hline
\end{tabular}

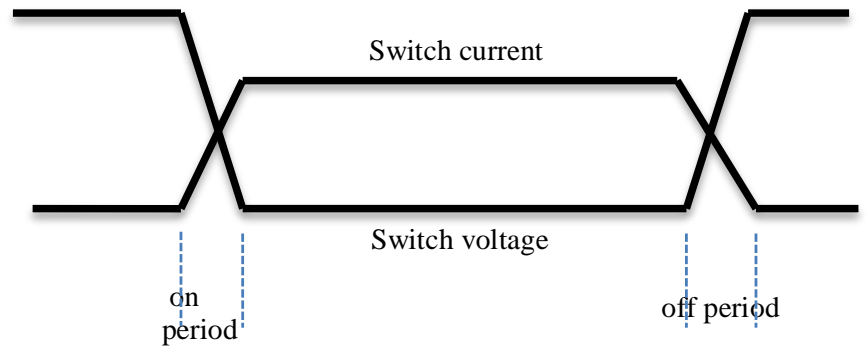

Figure 11. Representation of switching periods of semiconductor switches

$$
\eta_{\mathrm{EU}}=0.03 \eta_{5 \%}+0.06 \eta_{10 \%}+0.13 \eta_{20 \%}+0.10 \eta_{30 \%}+0.48 \eta_{50 \%}+0.2 \eta_{100 \%}
$$

where the subscript percentage values represent percentage sun irradiation. $\eta_{50 \%}$ is the PV system efficiency at $50 \%$ irradiation. For the presented system, $\eta_{\mathrm{EU}}$ is $77.45 \%$ 


\section{CONCLUSION}

A grid connected PV system is proposed which achieve maximum power point extraction from the PV panels and realize minimization of ground leakage current as well. HERIC transformerless inverter is employed for reducing the leakage current because of its high efficiency and reliability. dc-dc boost converter with incremental conductance MPP tracker achieve maximum power drawn from the PV panels at different insolation level. Three controllers are employed to the system for tracking the maximum power point, controlling the output voltage of boost converter and controlling the inverter switches. LCL filter is used to get sinusoidal inverter output voltage. Simulation results verify the effectiveness of the controllers and the overall system. Both conduction losses and switching losses of the semiconductor elements are studied and the system efficiency is estimated.

\section{REFERENCES}

[1] Jäger-Waldau, A., "PV Status Report 2017", JRC Science for Policy report, European Commission, 2017

[2] L. Zhang, K. Sun, Y. Xing, and M. Xing, "H6 transformerless Full-Bridge PV Grid-Tied Inverters", IEEE Transactions on Power Electronics, vol. 29, no. 3, 2014.

[3] F. Blaabjerg, R. Teodorescu, M. Liserre, and A. V. Timbus, "Overview of control and grid synchronization for distributed power generation systems," IEEE Transactions Industrial Electronics, vol. 53, no. 5, pp. 1398-1409, 2006.

[4] VDE 0126-1-1-2006, "Automatic disconnection device between a generator and the public low-voltage grid," DIN_VDE Normo, 2008.

[5] O. Lopez, F. D. Freijedo, A. G. Yepes, P. F. Comesana, J. Malvar, R. Teodorescu and J. Doval- Gandoy, "Eliminating Ground Current in a Transformerless Photovoltaic Application," IEEE Transaction on Energy Conversion, vol. 25, no. 1, pp. 140-147, 2010.

[6] A. K. Gupta, M. S. Joshi and V. Agarwal, "Improved Transformerless Grid-Tied PV Inverter Effectively Operating at Twice the Switching Frequency with Constant CMV and Reactive Power Capability", IEEE Journal of Emerging and Selected Topics in Power Electronics, 2019.

[7] M. Verma, S. Gangavarapu and A. K. Rathore, "Analysis and Design of a Novel Transformer-less-Inverter in GridConnected Photovoltaic System", $14^{\text {th }}$ IEEE Conference on Industrial Electronics and Applications (ICIEA), 2019.

[8] X. Guo, N. Wang, J. Zhang, B. Wang and M. K. Nguyen, "A Novel Transformerless Current Source Inverter for Leakage Current Reduction", IEEE Access, vol. 7, 2019

[9] H. V. Nguyen, D. H. Park, and D. C. Lee, "Single-Phase Transformerless PV Power Conditioning Systems with Low Leakage Current and Active Power Decoupling Capability", Journal of Power Electronics, vol. 18, no. 4, pp. 997-1006, 2018.

[10] Z. Liao, C. Cao, D. Qiu, and C. Xu, "Single-Phase Common-Ground-Type Transformerless PV Grid Connected Inverters", IEEE Access, vol. 7, 2019

[11] X. Guo, X. Jia, Z. Lu and J. M. Guerrero," Single Phase Cascaded H5 Inverter with Leakage Current Elimination for Transformer-less Photovoltaic System", Applied Power Electronics Conference and Exposition (APEC), IEEE, 2016.

[12] H. Li, Y. Zeng, T. Q. Zheng and B. Zhang, "A Novel H5-D Topology for Transformer-less Photovoltaic GridConnected Inverter Application", IEEE $8^{\text {th }}$ International Power Electronics and Motion Control Conference (IPEMC-ECCE Asia), 2016.

[13] A. P. Yadav and U. V. Patil, "Elimination of Leakage Current in Grid-Tied PV Applications", International conference on Electronics, Communication and Aerospace Technology (ICECA), 2019.

[14] L. A. Kumar, V. Indragandhi and N. S. Kumar, "Design and implementation of single-phase inverter without transformer for PV applications", IET Renewable Power Generation, vol. 12, no. 5, pp. 547-554, 2018.

[15] H. Xiao, L. Zhang, Z. Wang and M. Cheng, "A New Soft-Switching Configuration and Its Application in Transformerless Photovoltaic Grid-Connected Inverters", IEEE Transactions on Industrial Electronics, vol. 65, no. 12, pp. $9518-9527,2018$.

[16] D. Meneses, F. Blaabjerg, O. Garc'ia and J. A. Cobos, "Review and Comparison of Step-Up Transformerless Topologies for Photovoltaic AC-Module Application", IEEE Transactions on Power Electronics, vol. 28, no. 6, 2013.

[17] M. N. H. Khan, M. Forouzesh, Y. P. Siwakoti, L. Li, T. Kerekes and F. Blaabjerg, "A Classification of SinglePhase Transformerless Inverter Topologies for Photovoltaic Applications," 2018 IEEE Region Ten Symposium (Tensymp), 2018.

[18] G. Rizzoli, M. Mengoni, L. Zarri, A. Tani, G. Serra and D. Casadei, "Comparison of Single-Phase H4, H5, H6 Inverters for Transformerless Photovoltaic Applications", Industrial Electronics Society, IECON $2016-42^{\text {nd }}$ Annual Conference of the IEEE, pp. 3038- 3045, 2016.

[19] F. T. K. Suan, N. A. Rahim, and H. W. Ping, "Modeling, analysis and control of various types of transformer-less grid connected PV inverters," in Proc. IEEE CET, pp. 51-56, 2011.

[20] N. S. Jayalakshmi, Ankit Kumar and Ashish Kumar, "Analysis and Design of Single Phase High Efficiency Transformer Less PV Inverter Topology”, International Journal of Power Electronics and Drive System (IJPEDS), vol. 9, no. 2, pp. 730-737, 2018.

[21] S. Heribert, S. Christoph, and K. Jurgen, "Inverter for transforming a DC voltage into an AC current or an AC voltage," Europe Patent 1369 985(A2), 2003.

[22] J. Kanchikere, A. K. Ghosh, Kalyankumar, "Design and Simulation Analysis of Three-phase Transformer less Grid-connected PV Inverters," International Journal of Applied Power Engineering (IJAPE), vol.7, no.3, pp. 211-226, 2018. 
[23] Azadeh Safari and SaadMekhilef "Simulation and Hardware Implementation of Incremental Conductance MPPT with Direct Control Method Using Cuk Converter", IEEE Transaction on Industrial Electronics, vol. 5, no. 4, 2011.

[24] K. H. Hussein, I. Muta, T. Hoshino and M. osakada "Maximum Power Point Tracking: an Algorithm for Rapidly Chancing Atmospheric Conditions," IEE Proccedings - Generation - Transmision and Distribution, vol. 142, no. 1, pp. 59-64, 1995.

[25] O. Lagdani, M. Trihi and B. Bossoufi, "PV array connected to the grid with the implementation of MPPT algorithms (INC, P\&O and FL method)," International Journal of Power Electronics and Drive System (IJPEDS), vol. 10, no. 4, pp. 2084-2095, 2019.

\section{BIOGRAPHIES OF AUTHOR}

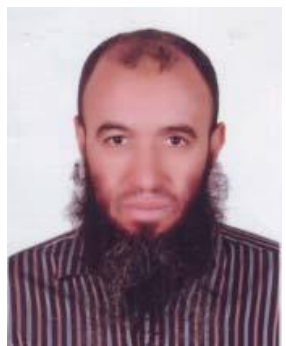

Essam Hendawi was born in Egypt, Giza, in 1968. He received his B.S. degree in Electrical Power and Machines Engineering from the Faculty of Engineering, Cairo University, Egypt, in 1992;his M.S. degree in Electrical Power and Machines Engineering from the Faculty of Engineering, Cairo University, Egypt, in 1998; and his Ph.D. degree in Electrical Power and Machines Engineering from the Faculty of Engineering, Cairo University, Egypt, in 2009. He is a Researcher in the Electronics Research Institute (ERI), Egypt, and he is currently working as an Assistant Professor in Electrical Engineering Department, College of Engineering, Taif University, Saudi Arabia. His research interests include electrical machine drives, DC-AC inverters, DC-DC converters, and renewable energy conversion. 